\title{
Study of Luders deformation in ultrafine low-carbon steel by the digital image correlation technique
}

\author{
V. A. Khotinov ${ }^{\dagger, 1}$, O. N. Polukhina ${ }^{1}$, D. I. Vichuzhanin², G. V. Schapov ${ }^{1}$, V.M. Farber ${ }^{1}$ \\ ${ }^{1}$ Ural Federal University n. a. the first President of Russia B. N. Yeltsin, 19 Mira St., Yekaterinburg, 620002, Russia \\ ${ }^{2}$ Institute of Engineering Science UB RAS, 34 Komsomolskaya St., Yekaterinburg, 620049, Russia
}

†khotinov@yandex.ru

\begin{abstract}
The studied steel was a low-carbon microalloyed steel of type 08G2B, used for pipes with an outer diameter of $1420 \mathrm{~mm}$ for natural gas transportation with an operation pressure of $11.8 \mathrm{MPa}$ with the chemical composition characterized by a low-carbon content ( 0.08 wt.\%) with additions of $\mathrm{Mn}, \mathrm{Cr}, \mathrm{Mo}, \mathrm{Ni}$ and microalloying elements $(\Sigma(\mathrm{Nb}, \mathrm{V}, \mathrm{Ti}) \approx 0.10 \mathrm{wt} \%$ ). Secondary refining and continuous casting followed by thermo-mechanical controlled processing (TMCP) with a strict temperature-reduction route and control of the post-deformation cooling rate are used to produce high-strength welded X80 and higher-grade pipes with an extremely ultrafine heterophase structure $(d=1-3 \mu \mathrm{m})$ and high Charpy energy of more than $250 \mathrm{~J} / \mathrm{cm}^{2}$ at $-40^{\circ} \mathrm{C}$. Usually sheet metal is not subjected to heat treatment. However, pipes can be heated by applying an anti-corrosion coating at $200-250^{\circ} \mathrm{C}$ or by welding in a heat affected zone, which initiates the strain aging effect (SAE). The appearance of SAE can also occur upon prolonged exposure of pipes in the area of climatic temperatures, as well as in the course of installation and operation of pipelines, which inevitably leads to a change in the mechanical properties of the metal. Luders deformation in ultrafine low-carbon microalloyed steel X80 has been studied upon tensile testing by the digital image correlation technique. Two mechanisms of Luders deformation are shown to be observed depending on the strain ageing effect. It is determined that the mechanical behavior of the material at the stage of uniform deformation strongly correlates with the type of Luders deformation.
\end{abstract}

Keywords: strain ageing, yield point, Luders deformation, digital image correlation technique, uniform deformation, plastic deformation components.

УДК: 620.172

\section{Изучение деформации Людерса в ультрадисперсной низкоуглеродистой стали методом корреляции цифровых изображений}

\author{
Хотинов В.А. ${ }^{\dagger, 1}$, Полухина О.Н. ${ }^{1}$, Вичужанин Д. И. ${ }^{2}$, Щапов Г. В. ${ }^{1}$, Фарбер В. М. ${ }^{1}$ \\ ${ }^{1}$ Уральский федеральный университет им. первого президента России Б. Н. Ельцина, \\ ул. Мира, 19, Екатеринбург, 620002, Россия \\ ${ }^{2}$ Институт машиноведения УрО РАН, ул. Комсомольская, 34, Екатеринбург, 620049, Россия
}

Объектом исследования являлась низкоулеродистая микролегированная трубная сталь типа 08Г2Б, используемая для производства магистральных газопроводов высокого давления, следующего химического состава (мас.\%): 0.08 С, $1.85 \mathrm{Mn}, 0.2 \mathrm{Ni}, 0.2 \mathrm{Cr}, 0.2 \mathrm{Mo}, \Sigma(\mathrm{Ti}-\mathrm{V}-\mathrm{Nb}) \approx 0.10$. Использование современных технологий литья (внепечная обработка стали, способ непрерывного литья заготовок) и прокатки (контролируемая прокатка с последеформационным ускоренным охлаждением) позволило получать высокопрочные сварные трубы класса прочности Х80 и выше с исключительно дисперсной гетерофазной структурой ( $d=1-3$ мкм) и высоким уровнем вязкости $\left(\mathrm{KCV}^{-40} \geq 250\right.$ Дж/см²). Обычно толстолистовой прокат из таких сталей не подвергается термической обработке. Однако трубы могут нагреваться при нанесении антикоррозионного покрытия до $t_{н}=200-250^{\circ} \mathrm{C}$ или при сварке в зоне термического влияния сварного шва при $t_{H}<A_{c 1}$, что инициирует эффект деформационного старения (ЭДС). Появление ЭДС также может происходить при длительном вылеживании изделий в районе климатических температур, при монтаже и эксплуатации конструкций, что неминуемо приводит к изменению механических свойств металла. Методом корреляции цифровых изображений (КЦИ) при испытаниях на растяжение изучены механизмы деформации Людерса в образцах низкоуглеродистой стали 08Г2Б с ультрадисперсной структурой после 
термообработки по различным режимам. Показано, что в зависимости от величины эффекта деформационного старения существует два вида деформации Людерса. На основе анализа полей продольной компоненты пластической деформации $\varepsilon_{y y}$ и ее профилей установлено, что механизм деформации Людерса определяет уровень напряжений и пластичность металла на равномерной стадии деформации.

Ключевые слова: деформационное старение, площадка текучести, деформация Людерса, метод корреляции цифровых изображений, равномерная стадия деформации, компоненты пластической деформации.

\section{1. Введение}

Интенсивные исследования эффекта деформационного старения сплавов на различной основе, проводимые в последние годы, можно связать с влиянием деформационного старения (ДС) на функциональные свойства и качество их поверхности [1-5]. Это актуально для строительных сталей нового поколения типа 08Г2Б c феррито-бейнитной (мартенситной) структурой, используемых для магистральных трубопроводов, судов, зданий и т. д. [6-8].

Подобные стали, изготовленные по технологии безрекристаллизационной контролируемой прокатки с ускоренным охлаждением, обладают рядом особенностей, делающих их благоприятным объектом для изучения деформационного старения. К ним можно отнести сверхнизкое содержание углерода, отсутствие перлита, близкую способность к деформационному упрочнению феррита и низкоуглеродистого бейнита (мартенсита) с ОЦК решеткой [9-11].

Деформационное старение действует на комплекс механических свойств металла трубопровода по-разному - с одной стороны, повышение предела текучести позволяет эксплуатировать трубопровод при более высоких рабочих напряжениях, с другой стороны, наблюдается охрупчивание металла, приводящее к преждевременному разрушению конструкции. В настоящее время оценка склонности сталей к деформационному старению проводится только по результатам испытаний на ударный изгиб образцов, предварительно подвергнутых холодной деформации $\varepsilon=10.0 \pm 0.5 \%$ и последующему старению при $250^{\circ} \mathrm{C}$ в течение 1 ч. Подобный подход значительно усложняет, а, зачастую, и не позволяет провести оценку величины деформационного старения и его влияния на другие механические свойства. Это требует развития новых методик аттестации металла при других видах механических испытаний, например, при испытаниях на растяжение.

Деформация Людерса происходит путем зарождения и распространения полос Чернова-Людерса (ПЧЛ) путем локализованного пластического течения металла вследствие дефицита свободных дислокаций, закрепленных атмосферами примесных атомов и/или частицами вторых фаз. На кривой растяжения появляются зуб и площадка текучести, значения которых определяются величиной эффекта деформационного старения, изменяются протяженность равномерной стадии $\delta_{\mathrm{p}}$ и показатель деформационного упрочнения $n$ на ней. Известно [12-15], что свойства деформационно состаренных сталей определяются соотношением между имеющейся в структуре плотностью дислокаций $\rho_{\text {д }}$ и плотностью их стопоров. Однако нераскрытым остает- ся вопрос о роли деформации Людерса в формировании механических свойств металла на последующих стадиях пластического течения.

Целью настоящей работы явилось изучение с использованием метода корреляции цифровых изображений особенностей деформации растяжением вплоть до образования шейки образцов из низкоуглеродистой стали 08Г2Б.

\section{2. Материалы и методики исследования}

Материалом исследования являлась трубная сталь 08Г2Б следующего химического состава (мас.\%): 0.08 С, $1.85 \mathrm{Mn}, 0.13 \mathrm{Mo}, \Sigma(\mathrm{Ti}-\mathrm{V}-\mathrm{Nb}) \approx 0.10,0.17 \mathrm{Cu}, 0.4 \mathrm{Si}, 0.19 \mathrm{Cr}$, $0.22 \mathrm{Ni}, 0.001 \mathrm{~S}, 0.013 \mathrm{P}$.

За исходное было принято состояние стали после безрекристаллизационной контролируемой прокатки с ускоренным охлаждением (КПУО). Обычно толстолистовой прокат из таких сталей не подвергается термической обработке. Однако изделия из них, в частности нефте- и газопроводные трубы, могут нагреваться при нанесении антикоррозионного покрытия до $t_{H}=200-250^{\circ} \mathrm{C}$ или при сварке в зоне термического влияния сварного шва при $t_{H}<A_{c 1}$, что инициирует эффект деформационного старения (ЭДС). Появление ЭДС также может происходить при длительном вылеживании изделий в районе климатических температур, при монтаже и эксплуатации конструкций, что неминуемо приводит к изменению механических свойств металла.

Исходя из этого, образцы в настоящем исследовании подвергались термообработке по режимам, моделирующим поведение металла в зоне термического влияния при сварке, а также нанесение антикоррозионного покрытия (нагрев проводился с печью):

- нагрев на $680^{\circ} \mathrm{C}$ без выдержки, охлаждение на воздухе (образец I);

- нагрев на $1000^{\circ} \mathrm{C}, \tau=30$ мин., закалка в воду + нагрев на $680^{\circ} \mathrm{C}, \tau=30$ мин., охлаждение на воздухе (образец II);

- нагрев на $250^{\circ} \mathrm{C}, \tau=30$ мин., охлаждение на воздухе (образец III).

Испытания на растяжение со скоростью $\dot{e}=2.7 \cdot 10^{-4} \mathrm{c}^{-1}$ плоских образцов толщиной 3 мм, шириной 20 мм и длиной рабочей части 60 мм проводились на машине Instron 8801, снабженной оптическим комплексом Strain Master для анализа полей перемещений и деформаций методом корреляции цифровых изображений (КЦИ). Согласно этой методике смещения точек на поверхности образца относительно оси нагружения соответствуют относительному удлинению $\delta$ (компонента $\varepsilon_{y y}$ ), относительному сужению $\psi\left(\varepsilon_{x x}\right)$ и относительному сдвигу $\gamma\left(\varepsilon_{x y}\right)$ [16-18]. В данной работе использовали анализ только компоненты $\varepsilon_{y y}$. 


\section{3. Результаты эксперимента}

Кривые растяжения $\sigma=f(\delta)$ образцов стали 08Г2Б после обработок по изученным режимам имеют зуб и площадку текучести различной формы и размеров, что свидетельствует о протекании в них в различном масштабе деформационного старения (Рис. 1). Также у образцов значительно различаются прочностные свойства - предел текучести $\sigma_{\text {т }}$ (т. 1 на Рис. 1 ), временное сопротивление $\sigma_{\text {в }}$ (т. 5), и пластические характеристики протяженность площадки текучести $\delta_{\text {т }}$ (участок 1-2) и равномерной $\delta_{p}$ (участок $3-5$ ) стадии деформации.

На Рис. 2 показаны поля компоненты тензора деформации $\varepsilon_{y y}$ в выбранных точках диаграмм растяжения исследованных образцов. В зависимости от природы сплава, условий растяжения в образце формируется одна, чаще несколько полос Чернова-Людерса.

В образце I деформация Людерса включала в себя образование и продольный рост полосы ЧерноваЛюдерса (ПЧЛ) и непрерывное увеличение степени деформации на ней (т. 1-2 на Рис. 2 и 3). Распределение деформации в ПЧЛ неоднородно. На полях компоненты $\varepsilon_{y y}$ это проявляется в виде апериодически расположенных полос, где степень деформации наибольшая (Рис. 2a), которым на профилях распределения $\varepsilon_{y y}$ по длине образца соответствует четыре небольших по высоте пологих пика (a, b, c, d на Рис. 3 a). Данные полосы интенсивного пластического течения, формирующиеся еще на упругой стадии деформации образцов и содержащие микроконцентраторы напряжений, рассматриваются как каналы течения [14].

На равномерной стадии характер распределения деформации по длине образца не меняется - степень деформации с растяжением образца постепенно возрастает по всей длине, и что при достижении $\sigma_{\text {в }}$ (т. 5 на Рис. 3) кривая $\varepsilon_{y y}-L_{\text {обр }}$ имеет вид плато с небольшими, близкими по величине пиками (Рис. 3 a).

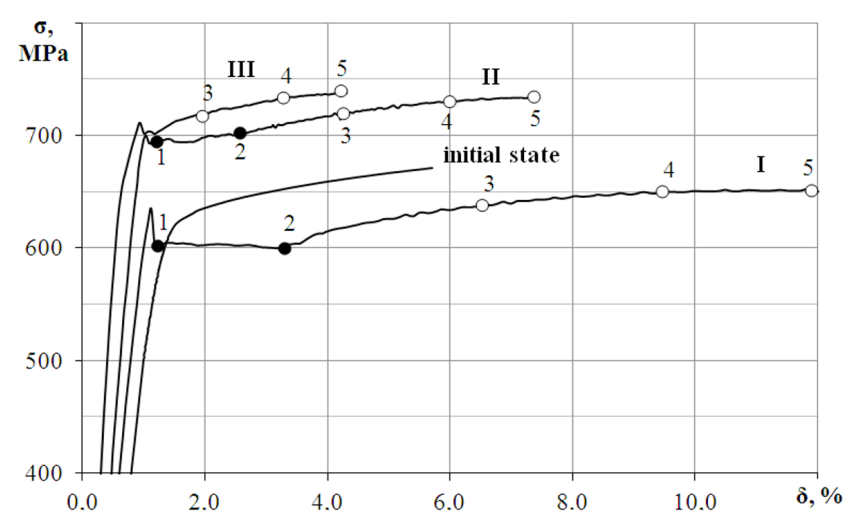

Рис. 1. Кривые растяжения образцов стали 08Г2Б в исходном состоянии и с разной величиной эффекта деформационного старения: I - слабый, II - средний, III - сильный; участок 1-2 - площадка текучести; участок 3-5 равномерная стадия деформации.

Fig. 1. Stress-strain curves of ultrafine low carbon steel specimens in initial state and with different strain ageing effect: specimen I - low, II - medium, III - strong; marks 1-2 - yield point, marks 3-5 uniform deformation.
Механическое поведение при растяжении образца II связано с возникновением и распространением восьми попарно пересекающихся ПЧЛ. В начале площадки текучести на поверхности образца наблюдается одна ПЧЛ (т. 1 на Рис. 2 b), которой на профиле $\varepsilon_{y y}=f\left(L_{\text {обр }}\right)$ соответствует максимум $\varepsilon_{y y} \sim 2.0 \%$ в центре (Рис. $3 \mathrm{~b}$ ). Вторая ПЧЛ, достигнув противоположной боковой поверхности образца, инициирует здесь зарождение третьей ПЧЛ, тогда как первая ПЧЛ приводит аналогичным образом к возникновению четвертой ПЧЛ (пунктирные линии на Рис. 2b).

Две пересекающиеся ПЧЛ формируют очаг деформации (ОД), состоящий из четырех периферийных остатков ПЧЛ и центральной области в месте их пересечения. Возникновение к концу площадки текучести нескольких ОД обусловливает «пятнистое» распределение деформации на исследуемой поверхности образца (т. 2 на Рис. 3 b).

На равномерной стадии деформации на осевых профилях $\varepsilon_{y y}=f\left(L_{\text {обр }}\right)$ сохраняются четыре пика (a, b, c, d), апериодически расположенные по длине образца (т. 3-5 на Рис. 2b, Рис. 3 b). Лидирующим является первый пик (a), который имеет наиболее быстрый рост $\varepsilon_{y y}$ и непрерывное смещение в сторону больших значений $L_{\text {обр }}$. К окончанию равномерной стадии (т. 5 на Рис. 2 b и Рис. $3 \mathrm{~b}$ ) деформация сосредоточена преимущественно в этом очаге деформации благодаря отставанию роста других.

В образце III к началу площадки текучести зародыш ПЧЛ прорастает на всю ширину образца (т. 1 на Рис. 2 c), но весьма быстро у противоположной боковой поверхности образца возникает и растет зародыш второй ПЧЛ, образуя к концу площадки текучести очаг деформации, состоящий из центральной области и четырех выходящих из нее углов периферийных остатков ПЧЛ (показаны пунктиром, см. т. 2 на Рис. 2 c).

На профилях $\varepsilon_{y y}=f\left(L_{\text {обр }}\right)$ появлению первой ПЧЛ соответствует сравнительно небольшой по величине пик $\left(\varepsilon_{y y} \sim 0.7 \%\right)$ (Рис. $\left.3 c\right)$. Появление второй ПЧЛ, пересекающей первую, приводит к росту $\varepsilon_{y y}$ при образовании центрального очага деформации. Развитие пластического течения на равномерной стадии деформации связано с быстрым увеличением высоты и площади под кривой $\varepsilon_{y y}=f\left(L_{\text {обр }}\right)$, отвечающей очагу деформации, слабо дрейфующего к середине образца.

\section{4. Обсуждение результатов}

Различия в виде диаграмм растяжения, параметров КЦИ у образцов стали 08Г2Б, термообработанных по различным режимам, несомненно, связаны с величиной ЭДС. Для оценки величины ЭДС был использован подход, в основе которого лежит изменение способности металла к равномерному пластическому течению под действием этого эффекта, в результате чего с возрастанием его величины происходит изменение трех основных параметров:

- повышение предела текучести $\sigma_{\text {т }}$ (параметр $D_{1}$ );

- уменьшение угла наклона кривой $\sigma=f(\delta)$ на равномерной стадии, отражаемое повышением отношения $\sigma_{\mathrm{T}} / \sigma_{\mathrm{B}}\left(\right.$ параметр $\left.D_{2}\right) ;$ 

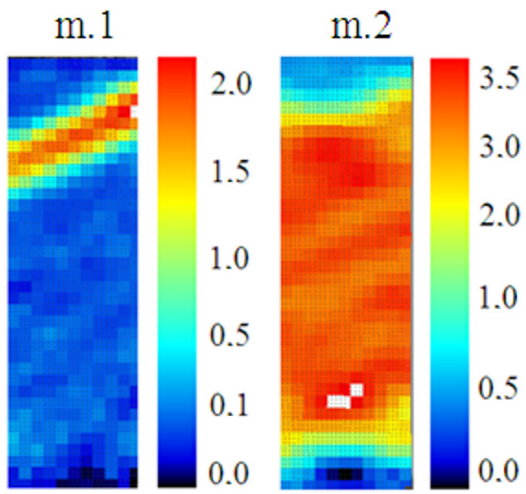

$\mathrm{m} .3$
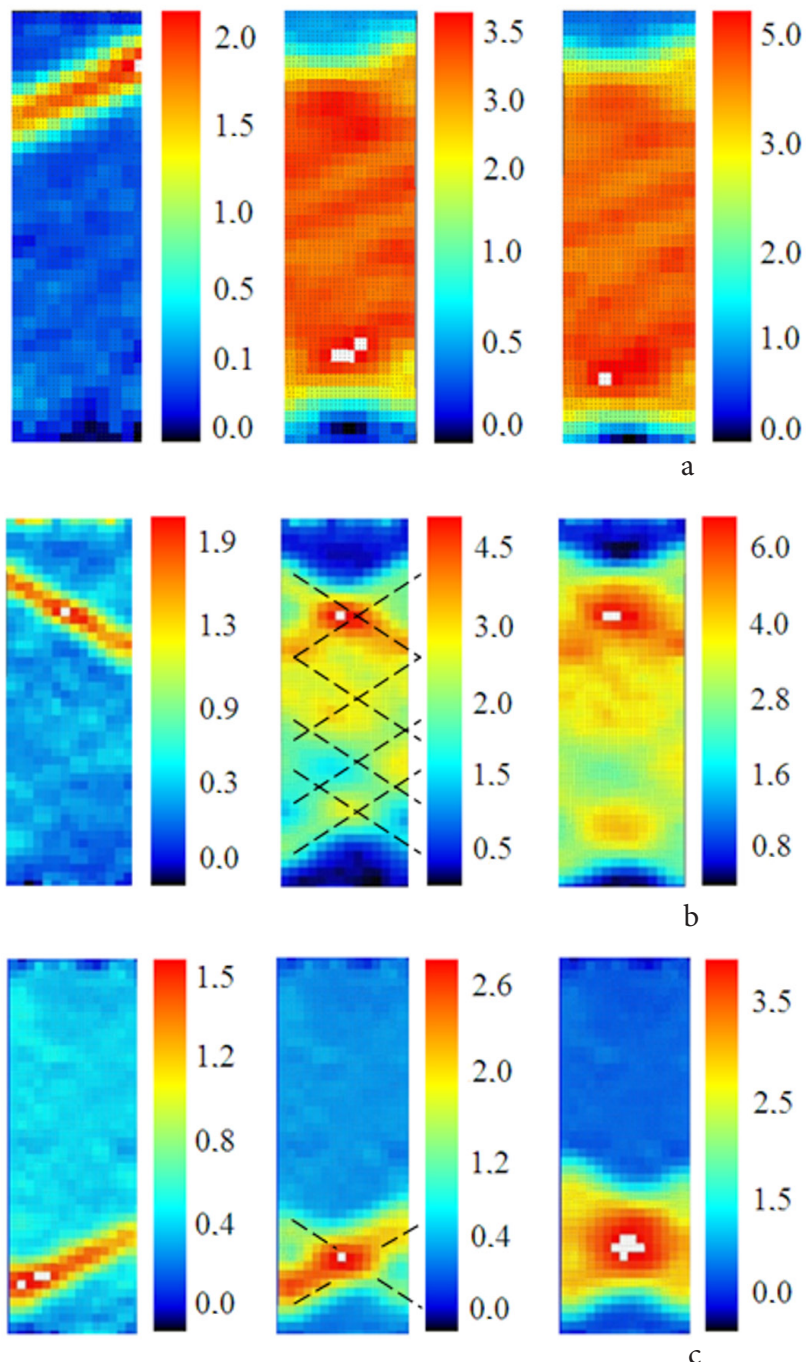

m.4
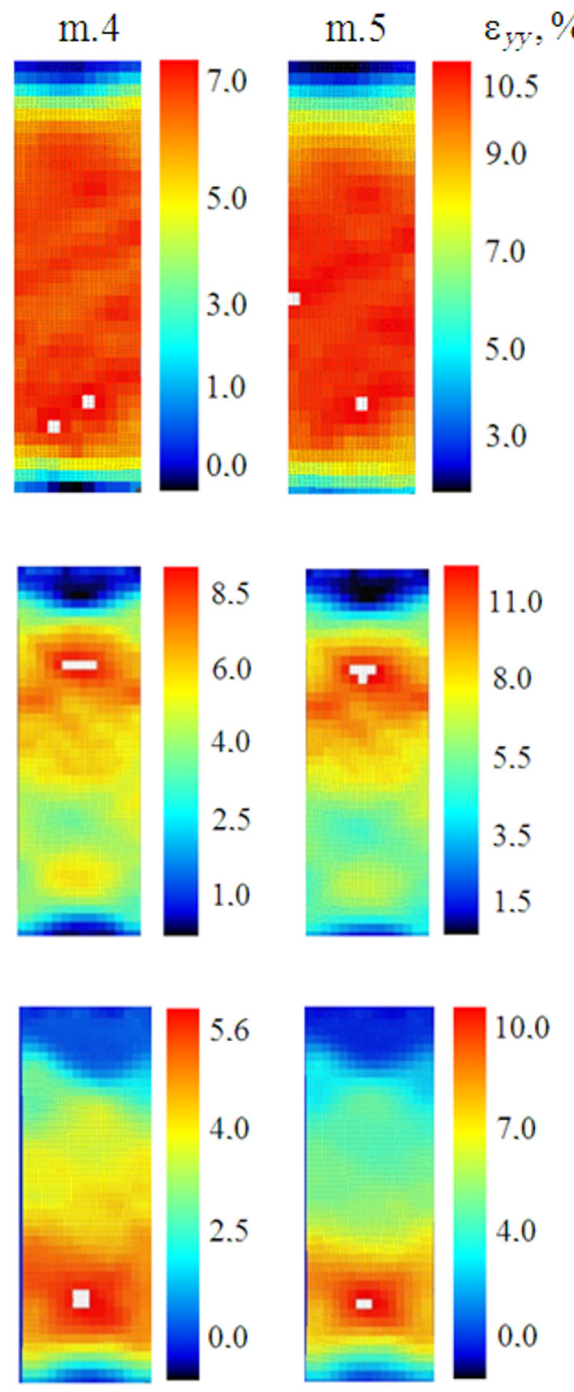

Pис. 2. (Color online) Поля продольной компоненты тензора деформации $\varepsilon_{y y}$ на площадке текучести (т. 1-2 на Рис. 1) и равномерной стадии (т. 3 - 5 на Рис. 1): образец I (a), образец II (b), образец III (c).

Fig. 2. (Color online) DIC fields of plastic deformation component $\varepsilon_{y y}$ at the yield point (marks 1 and 2 in Fig. 1) and at uniform stage (marks 3-5 in Fig. 1): specimen I (a), specimen II (b), specimen III (c).

- снижение протяженности равномерной стадии $\delta_{\mathrm{p}}$ (параметр $D_{3}$ ).

Наиболее слабый эффект деформационного старения наблюдается в образце I. Примем для этого случая, что прирост предела текучести $\Delta \sigma_{\mathrm{T}}=0$, тогда вклад прироста предела текучести в величину ЭДС для образцов II и III можно выразить как

$$
D_{1}=\frac{\Delta \sigma_{\mathrm{T}}}{\Delta \sigma_{\mathrm{T}}^{\max }},
$$

где $\Delta \sigma_{\mathrm{T}}^{\max }=100$ МПа для образца III (Табл. 1).

Вклад изменения наклона кривой на равномерной стадии в величину ЭДС можно выразить как

$$
D_{2}=\frac{\sigma_{\mathrm{T}}}{\sigma_{\mathrm{B}}},
$$

а вклад изменения протяженности равномерной стадии $\delta_{\mathrm{p}}$

$$
D_{3}=1-\frac{\delta_{\mathrm{p}}}{\delta_{\mathrm{p}}^{\max }},
$$

где $\delta_{\mathrm{p}}^{\max }$ - максимальная протяженность равномерной стадии деформации $\left(\delta_{\mathrm{p}}^{\mathrm{max}}=10.6 \%\right.$ для образца I).
Суммарный вклад всех выделенных характеристик в величину ЭДС можно приближенно описать параметром деформационного старения $D$, используя правило смесей и приняв, что вклады упрочнения $\left(\Delta \sigma_{\mathrm{T}} \rightarrow K_{1}=0.50\right)$ и изменения равномерной стадии деформации $\left(\sigma_{\mathrm{T}} / \sigma_{\mathrm{B}}, \delta_{\mathrm{p}} \rightarrow K_{2}+K_{3}=0.50\right)$ равны

$$
D=0.50 \cdot D_{1}+0.25 \cdot D_{2}+0.25 \cdot D_{3} .
$$

Таким образом, параметр $D$, являясь относительной характеристикой, позволяет ранжировать образцы по величине ЭДС в диапазоне от наименьшего до наибольшего его проявления, что было прослежено на серии образцов после различных термообработок $[19,20]$. В то же время на основе параллельного изучения зарождения и роста ПЧЛ с помощью метода КЦИ и механических свойств показано, что определенной величине $D$ соответствует свой вид деформации Людерса в образцах исследованной стали.

При минимальной величине $D=0.23$ (Табл. 1) у образца I происходит формирование одной полосы Чернова-Людерса и полосовой механизм деформации 

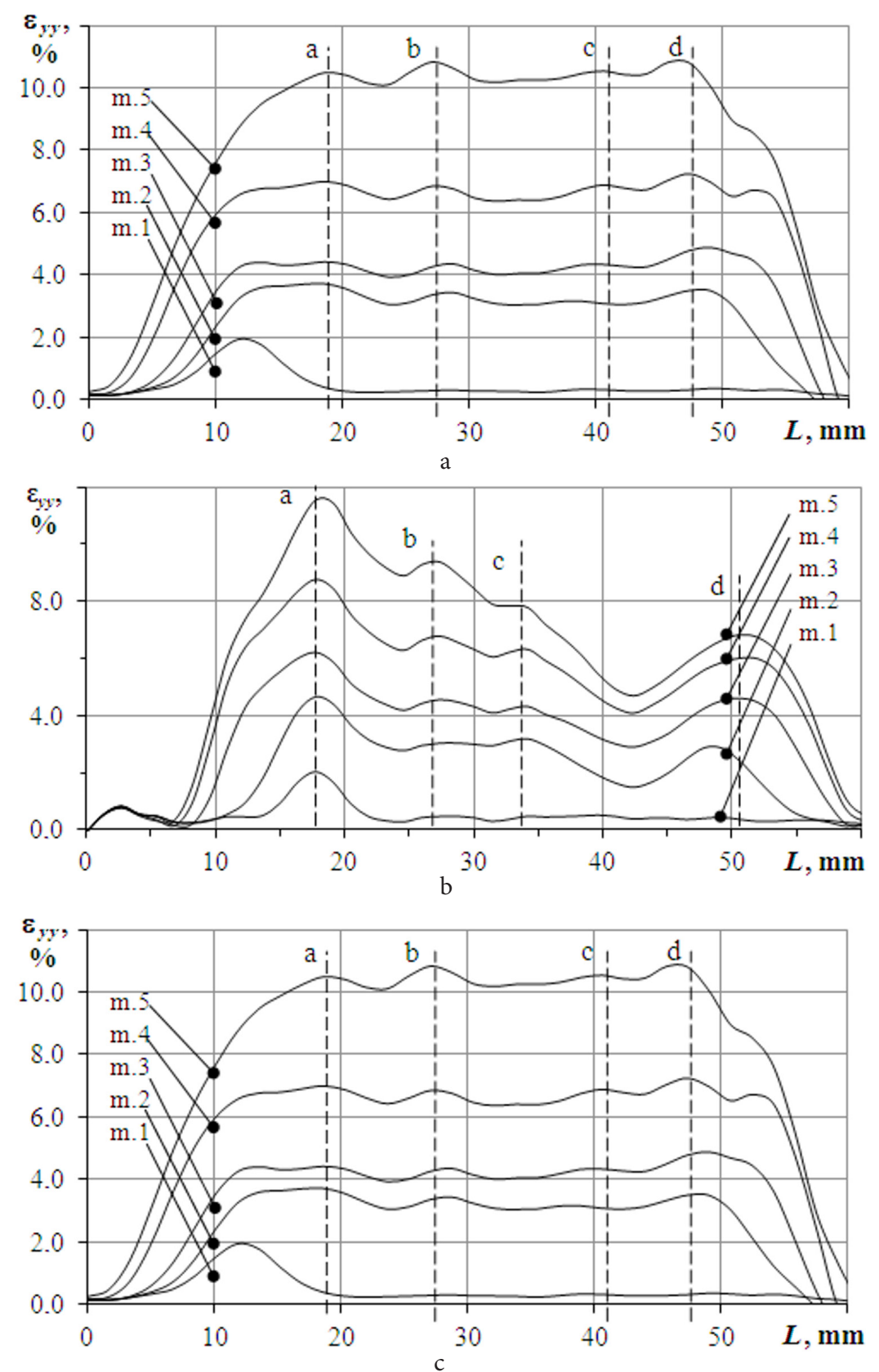

Рис. 3. Профили распределения компоненты $\varepsilon_{y y}$ вдоль центральной оси по длине образца $L_{\text {обр }}$ образец I (a), образец II (b), образец III (c). Fig. 3. DIC profiles of component $\varepsilon_{y y}$ through the center of calculated specimen length $L$ : specimen I (a), specimen II (b), specimen III (c).

Табл. 1. Оценка величины эффекта деформационного старения $D$ по изменению параметров равномерной стадии деформации. Table 1. Determination of the strain ageing parameter $D$ by changing the parameters of uniform deformation stage.

\begin{tabular}{|c|c|c|c|c|c|c|c|c|}
\hline $\begin{array}{l}\text { Образец } \\
\text { Specimen }\end{array}$ & $\begin{array}{l}\sigma_{\mathrm{t}}, \mathrm{M} а \\
\sigma_{\mathrm{y}^{\prime}}, \mathrm{MPa}\end{array}$ & $\begin{array}{l}\Delta \sigma_{\mathrm{T}}, \mathrm{M} \text { Па } \\
\Delta \sigma_{\mathrm{y}} \mathrm{MPa}\end{array}$ & $D_{1}$ & $\begin{array}{l}\sigma_{\mathrm{T}} / \sigma_{\mathrm{B}} \\
\sigma_{\mathrm{y}} / \sigma_{\mathrm{TS}}\end{array}$ & $D_{2}$ & $\begin{array}{l}\delta_{\mathrm{p}}, \% \\
\delta_{\mathrm{u}^{\prime}}, \%\end{array}$ & $D_{3}$ & $D$ \\
\hline I & 605 & 0 & 0 & 0.93 & 0.93 & 10.6 & 0 & 0.23 \\
\hline II & 695 & 90 & 0.90 & 0.95 & 0.95 & 6.3 & 0.41 & 0.79 \\
\hline III & 705 & 100 & 1.00 & 0.95 & 0.95 & 3.4 & 0.68 & 0.91 \\
\hline
\end{tabular}

Людерса, обеспечивающий рост очага деформации на площадке текучести в пределах всей рабочей части образца.

В образцах II и III ( $D=0.79$ и 0.91 , соответственно), в которых очаг деформации состоит из центральной области, где произошло пересечение двух ПЧЛ, и их периферийных участков, реализуется другой механизм деформации Людерса, которая не заканчивается на площадке текучести.
Если полосовой рост одной ПЧЛ тождественен не вызывающему упрочнения одинарному скольжению на I стадии деформации монокристаллов [13], то рост центральной области, где дислокации, внесенные пересекающимися ПЧЛ, принадлежат двум системам скольжения, можно рассматривать как аналог II линейной стадии деформации монокристаллов. Такой механизм деформации Людерса в образцах II и III приводит к тому, что очаг деформации даже 
при максимальном размере занимает далеко не всю рабочую часть образца.

Механизм деформации Людерса накладывает отпечаток на распределение деформации по длине образца на равномерной стадии: если к моменту достижения напряжения $\sigma_{\text {в }}$ кривая $\varepsilon_{y y}-L_{\text {обр }}$ в образце I имеет вид близкий к плато, то в образцах II и III куполообразный вид, где расположение вершины купола предопределяет место образования шейки и магистральной трещины на сосредоточенной стадии деформации [19].

\section{5. Заключение}

Для оценки величины эффекта деформационного старения в образцах стали 08Г2Б предложен параметр $D$, в основе которого лежит изменение характеристик площадки текучести и равномерной стадии деформации $\left(\Delta \sigma_{\mathrm{T}}, \sigma_{\mathrm{T}} / \sigma_{\mathrm{B}}\right.$, $\left.\delta_{\mathrm{p}}\right)$. Анализ полей продольной компоненты пластической деформации $\varepsilon_{y y}$ и ее профилей, полученных методом КЦИ при растяжении образцов, показал, что в зависимости от величины $D$ существует два вида деформации Людерса.

При минимальном $D=0.23$ деформация Людерса происходит путем расширения одиночной полосы Чернова-Людерса вдоль оси нагружения. При $D \geq 0.80$ деформация Людерса осуществляется расширением центральной области, сформировавшейся при пересечении двух ПЧЛ, и перемещением их четырех оставшихся периферийных участков.

Вид деформации Людерса приводит к различному распределению деформации вдоль оси растяжения образцов $L_{\text {обр }}$ на равномерной стадии и к моменту достижения $\sigma_{\text {в }}$ весьма однородному (кривая $\varepsilon_{y y}-L_{\text {обр }}$ имеет горизонтальное плато) при первом виде деформации Людерса и локализованному (кривая $\varepsilon_{y y}-L_{\text {обр }}$ с ярко выраженным куполом) при втором.

Благодарности/Acknowledgements. Работа выполнена в УрФУ при финансовой поддержке постановления № 211 Правительства Российской Федераиии, контракт № 02. А03.21.0006, а также в ИМАШ УрО РАН в рамках темы государственного задания №0391-2016-0004./The work was performed cooperatively in Ural Federal University with the support of the Government of the Russian Federation, resolution no. 211, contract no. 02. A03.21.0006 and in Institute of Engineering Science (Ural Branch of RAS) within the state theme no. 0391-2016-0004.

\section{Литература/References}

1. R. Rana, S.B. Singh. Automotive Steels - Design, Metallurgy, Processing and Applications. Woodhead Publishing (2017) $478 \mathrm{p}$.

2. T. Waterschoot, A. De, S. Vandeputte, B. De Cooman. Met. Trans. A. 34 (13), 781 (2003). Crossref

3. M. A. Smirnov, I. Yu. Pyshmintsev, O. V. Varnak et al. Steel in Translation. 46 (1), 58 (2016). Crossref

4. T. Liu, H. Hou, X. Zhang et al. Mat. Sci. Eng. A. 726, 160 (2018). Crossref

5. V.I. Danilov, V.V. Gorbatenko, L. B. Zuev, D. V. Orlova,
L. V. Danilova. Izvestiya. Ferrous Metallurgy. 60 (10), 831 (2017). (in Russian) [В.И. Данилов, В.В. Горбатенко, Л.Б. Зуев, Д.В. Орлова, Л.В. Данилова. Известия Высших Учебных Заведений. Черная Металлургия. 60 (10), 831 (2017).] Crossref

6. W.G. Zhao, M. Chen, S.H. Chen, J.B. Qu. Mater. Sci. Eng. A. 550, 418 (2012). Crossref

7. V.N. Chuvildeev. Vliyaniye stareniya na ekspluatatsionnyye svoystva staley magistral'nykh gazoprovodov. In: Problems of aging of steels for gas pipelines. Nizhny Novgorod, University book (2006) p. 18-67. (in Russian) [В.Н. Чувильдеев. Влияние старения на эксплуатационные свойства сталей магистральных газопроводов. В кн.: Problemy stareniya staley magistral'nykh truboprovodov. Н. Новгород, Университетская книга (2006) с. 18-67.]

8. S. Hosseini, A. Heidapour, F. Collins, C. R. Hutchinson. Constr. and Build. Mat. 77, 83 (2015). Crossref

9. A.B. Arabey, V.M. Farber, I.Yu. Pyshmintsev etal. Izvestiya. Ferrous Metallurgy.55(1),30(2012).(in Russian) [А.Б. Арабей, В.М. Фарбер, И. Ю. Пышминцев и др. Изв. Вузов. Черная металлургия. 1, 30 (2012).] Crossref 10. S.-Y. Shin. Met. Trans. A. 44 (6), 2613 (2013). Crossref

11. B. Tanguy, T. T. Luu, G. Perrin et al. Int. J. Pressure Vessels and Piping. 85, 322 (2008). Crossref

12. J. Pelleg. Mechanical properties of materials. Dordrecht, Springer (2013) 634 p. Crossref

13. M. A. Shtremel. Strength of alloys: Vol. 2: Deformation. Moscow, MISIS (1997) 527 p. (in Russian) [M.А. Штремель. Прочность сплавов. Ч. 2: Деформация. Москва, МИСИС (1997) 527 с.]

14. V.M. Farber, O. V. Selivanova, V.A. Khotinov, etal. Deformatsionnoye stareniye $\mathrm{v}$ stalyakh. Yekaterinburg, URFU (2018) 72 p. (in Russian) [В. М. Фарбер, О. В. Селиванова, В. А. Хотинов и др. Деформационное старение в сталях. Екатеринбург, УрФУ (2018) 72 с.]

15. N. Ormsuptave, V. Ulthaisangsuk. Mat. Design. 118, 314 (2017). Crossref

16. V.E. Vildeman, M.P. Tretyakov, R.V. Bulbovich etal. Experimental studies of the properties of materials under complex thermomechanical processing. Moscow, Fizmatlit (2012) 204 p. (in Russian) [В.Э. Вильдеман, М.П. Третьяков, Р.В. Бульбович и др. Экспериментальные исследования свойств материалов при сложных термомеханических воздействиях. Москва, Физматлит (2012) 204 с.]

17. M. A. Sutton, J.-J. Orteu, H. W. Schreier. Image correlation for shape, motion and deformation measurements. University of South Carolina (2009) 364 p.

18. S. Avril, F. Pierron, M. A. Sutton. Mech. Mater. 40 (9), 729 (2008). Crossref

19. V.A. Khotinov, O.N. Polukhina, O.V. Selivanova, V.M. Farber. Materialovedenie. 5, 8 (2018). (in Russian) [В.А. Хотинов, О.Н. Полухина, О.В. Селиванова, В. М. Фарбер. Материаловедение. 5, 8 (2018).]

20. V.A. Khotinov, O.V. Selivanova, V.M. Farber. Deformatsiya i Razrushenie materialov. 1, 37 (2019). (in Russian) [В.А. Хотинов, О.В. Селиванова, В.М. Фарбер. Деформацияи разрушение материалов. 1, 37 (2019).] Crossref 